\section{Commentary: Wire-based cannula exchange when time is of the essence}

\author{
Benjamin S. Bryner, MD
}

As extracorporeal membrane oxygenation (ECMO) is used for a wider range of indications and patients and is initiated at a larger number of institutions, ECMO component failure will become more common as well. Despite innumerable advances in cannulas, pumps, and monitoring systems since the early days of ECMO, every circuit is still susceptible to breakage of plastic connectors, tubing, or cannulas themselves. Patients on ECMO are at risk for this complication after interhospital transfer as well as intrahospital transport to undergo studies, procedures, etc.

Abdullah and colleagues ${ }^{1}$ describe, and more importantly demonstrate on video, a method of exchanging a broken arterial cannula in a patient with an unsalvageable cannula but who continued to require ECMO. This method requires relatively little setup and can be performed in the intensive care unit if there is no time for transport the patient to the operating room (OR). By avoiding cutdown and open vascular exposure, this method saves time and avoids the inevitable increased bleeding that follows a cutdown without being able to definitively repair the involved vessel.

Fractures of plastic components of ECMO circuits, especially those on the post-pump side of the circuit, are rarely able to be temporized with external compression (as demonstrated by the authors here), which is sometimes attempted with bone wax, adhesives, or tape. Recognition of the problem immediately is essential, as is mobilization of the necessary personnel for a new cannulation if it

From the Division of Thoracic and Cardiovascular Surgery, Department of Surgery, Duke University, Chapel Hill, NC.

Disclosures: The author reported no conflicts of interest.

The Journal policy requires editors and reviewers to disclose conflicts of interest and to decline handling or reviewing manuscripts for which they may have a conflict of interest. The editors and reviewers of this article have no conflicts of interest.

Received for publication Feb 27, 2020; revisions received Feb 27, 2020; accepted for publication March 8, 2020; available ahead of print April 6, 2020.

Address for reprints: Benjamin S. Bryner, MD, Division of Thoracic and Cardiovascular Surgery, Department of Surgery, Duke University, Durham, NC 27514 (E-mail: ben.bryner@duke.edu).

JTCVS Techniques 2020;2:88-9

2666-2507

Copyright $(2020$ The Authors. Published by Elsevier Inc. on behalf of The American Association for Thoracic Surgery. This is an open access article under the CC BY-NCND license (http://creativecommons.org/licenses/by-nc-nd/4.0/).

https://doi.org/10.1016/j.xjtc.2020.03.020

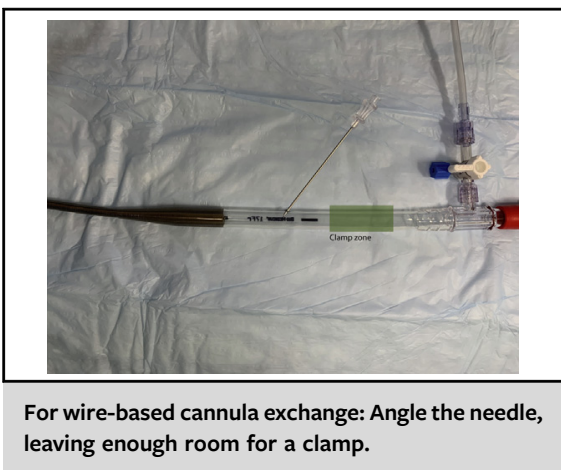

CENTRAL MESSAGE

Careful exchange of a broken

femoral arterial ECMO cannula

can be accomplished safely over

a wire while avoiding an open

cutdown.

becomes necessary. Inserting a wire through the side of the cannula must be done clear of the wire-wound portion and with enough clearance distal to the wire insertion site to allow clamping of the cannula. The cannula, the insertion site, and a generous length of ECMO tubing to allow for clamping and re-connecting to a new cannula, must all be cleaned with sterile prep. Additional blood loss will occur (even if the pump is slowed or stopped) through the needle, so all equipment must be prepared before puncture, and blood products should be available. When removing the old cannula over the wire, great care must be taken as the cannula may not slide over a wire as easily as devices designed to slide over a wire will do, and the wire can be dragged out of the artery with it. An assistant should scrub and be directed specifically to hold pressure around the artery after the cannula is removed. Obviously, the old cannula will come out without a dilator, but an identically sized (or larger) cannula with the dilator in place must be ready to exchange over the wire once the old cannula is clear. Fluoroscopy is important for proper replacement of venous cannulas but can be omitted for arterial reinfusion cannulas as in this case.

Performing this procedure in the OR offers a safety net in case the replacement does not go smoothly: cutdown can immediately be performed, another site for cannulation can be prepared, and additional dilators or wires may be more immediately available. Any problem with insertion of the new cannula should prompt immediate transfer to 
the OR for a cutdown and investigation. Abdullah and colleagues should be commended for having the presence of mind to videotape this innovative solution to a timesensitive problem.

\section{Reference}

1. Abdullah M, Shah A, Madathil RJ, Kacsorowski D. Awake, percutaneous, bedside extracorporeal membrane oxygenator arterial cannula exchange. J Thorac Cardiovasc Surg Tech. 2020;2:84-5. 